\title{
Recent Developments in the Isolation and Structure Elucidation of Naturally Occurring Iridoid Compounds
}

Peter Junior

Institut für Pharmazeutische Biologie der Universität Düsseldorf, Universitätsstraße 1, D-4000 Düsseldorf 1, Federal Republic of Germany

Received: December 7, 1988

\section{Abstract}

Naturally occurring iridoid compounds are widely distributed in sympetalous plants and they serve as important taxonomic markers. In this survey their classification is given from the biosynthetic point of view. The recent literature concerning isolation and structure elucidation is reviewed, data on chromatography and spectroscopy, new types of iridoids and secoiridoids as well as new sugar moieties as constituents of iridoid glycosides are presented.

\section{Key words}

Iridoids, secoiridoids, isolation, structure, new types.

\section{Introduction}

Iridoids represent a large group of natural monoterpenoid compounds; they have been found to occur in a variety of animal species and to be constituents of a number of orders and plant families within the dicotyledons.

The name iridoid has been derived from iridodial (1), iridomyrmecin (3), and related compounds isolated from the defence secretion of Iridomyrmex species, a genus of ants, constituting a generic term for monoterpene derivatives characterised by a cyclopenta[c]pyran skeleton in the narrow sense of the term. In order to simplify the nomenclature of iridoids, this skeleton has been denoted as "iridane" $(1,2)$ (cis-2-oxabicyclo[4.3.0]nonane), a non-systematic name, common in literature up to now but first proposed for 1,2-dimethyl-3-(2-propyl)-cyclopentane (3).

\section{Classification of naturally occurring iridoid compounds}

Naturally occurring iridoid compounds have been classified by several authors into different subgroups on the basis of their demonstrated or postulated biosynthesis as well as on the basis of chemical properties<smiles>C=C(C=O)C1CC[C@@H](C)C1C=O</smiles>

dolichodial (2)<smiles>CC(C=O)C1CC[C@@H](C)C1C=O</smiles>
cyclopentanoid
monoterpenes<smiles>CC1CCC2C(C)C(=O)OCC12</smiles>

iridomyrmecin (3)<smiles>CC1=COC(O)(O)C2[C@@H]1CC[C@H]2C</smiles>

"iridene"

skeleton

iridodial (1)
(1) volatile iridoids aucubin (4)

(3) chromogenic iridoid glycosides

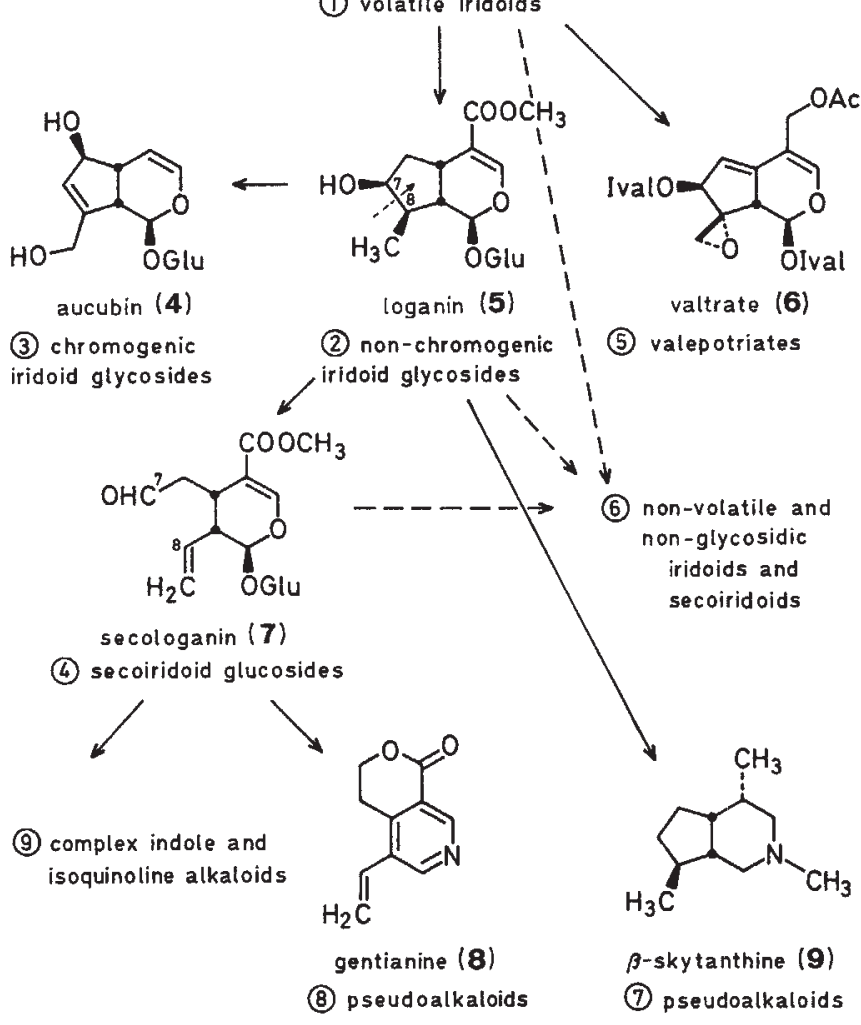

Scheme A Classification of natural iridoid compounds (according to Ref. 11) including compounds of a) volatile oils and b) defensive secretions. 
(4-12). According to Hegnauer's classification (11), natural iridoid compounds in the broadest sense are represented by nine structural groups, consisting of cyclopentanoid monoterpenes and secoiridoids, in general characterised by the structural feature of a 7,8-seco ring, including pseudalkaloids as well as complex indole- and isochinolinetype alkałoids (Scheme A). Therefore, the assumed extent of naturally occurring iridoids should consist of far more than 1000 compounds.

Other authors like El-Naggar and Beal (9) have summarised only iridoid glycosides, usually but not necessarily containing glucose and secoiridoid glucosides and non-glycosidic compounds, and omitting all nitrogencontaining iridoids. Simple pseudoalkaloids like gentianine (8) and others have been considered as artefacts formed by replacement of oxygen by nitrogen in genuine iridoids upon ammonia treatment during extraction. The important complex alkaloids of the ajmalicine-, catharanthine-, and ibogamine-types, however, containing a secoiridoid moiety in the molecule are taken to constitute a clear and well defined group by themselves.

In the above-mentioned survey (9), 258 compounds are listed together with all physical data available at that time. They were divided into ten subgroups according to different numbers of carbons in the iridaneskeleton and increasing state of oxidation as well as different substitution patterns.

The carbon skeleton of iridoids in general consists of ten or nine and rarely (unedoside; 10) eight carbons, but also compounds containing thirteen (fulvoplumierin; 11), fourteen (plumericin; 12) and nineteen carbons (oruwacin; 13) are known.

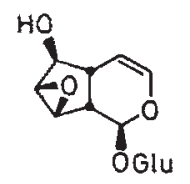

unedoside $(10)$<smiles>C/C=C/C=C1\C=CC2C(C(C)=O)=COC(=O)C12</smiles>

fulvoplumierin (11)

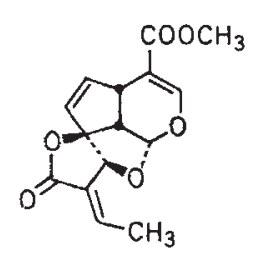

plumericin (12)

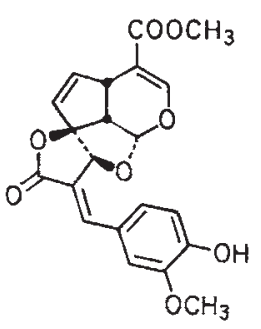

oruwacin (13)
Recently, Inouye and Uesato (12) have surveyed the biosynthesis of iridoids and secoiridoids and presented another classification from the biogenetic point of view and hence dividing the compounds conventionally into non-glycosidic iridoids (including pseudoalkaloids of the skytanthine-type), iridoid glycosides, and secoiridoid glucosides, while obviously excluding non-glucosidic secoiridoids and gentianine-type pseudoalkaloids. Whereas the first two groups are not subdivided any further, the third group has been subdivided into four subgroups from the view of biosynthetic pathways and structural similarities.

At that time (1986), approximately 300 iridoid glycosides, 60 secoiridoid glucosides, and 90 nonglycosidic iridoids as well as about 40 alkaloidal glucosides (13) with close relationships to the secoiridoid group were known.

Up to now, while retaining a similar classification but omitting the glucosidic alkaloids of the vincosideand ipecoside-types, the number of known compounds has increased to about 650 according to a computer-aided research through Chemical Abstracts. Thus, the rapid expansion in the fields of isolation and structure elucidation of new natural iridoid compounds is conspicously demonstrated.

It should be noted that pseudoalkaloids have been included in this number because, in the meantime, several of these compounds have been isolated from natural sources without ammonia treatment. Thus, the formation of artefacts can be excluded. In this connection, studies on constituents of Bignoniaceae and Scrophulariaceae plants should be mentioned, since these clearly indicate that compounds like boshniakine (14) (14, $15)$ and rhexifoline $(15)(16,17)$ are natural constituents. On the other hand, rhexifoline could be formed as an artefact by treatment of the intact iridoid glucoside penstemonoside (16) with $\beta$-glucosidase and ammonia (18).

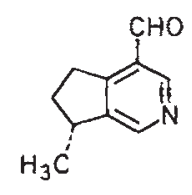

boschniakine (14)<smiles>COC(=O)c1cncc2c1[C@H](O)CC2C</smiles>

(15)<smiles>CC(=O)C1=CO[C@@H](O)C2C(C)C[C@@H](O)[C@H]12</smiles>

penstemonoside (16)

\section{Branches of iridoid research}

The rapid progress already mentioned can be observed in all fields of iridoid research in the widest sense. In this connection, the following branches may be considered as essential and important: isolation and separation, structure elucidation, biosynthesis, taxonomical significance, and biological activities. All these branches of research are closely connected and complement each other with regard to our actual knowledge of naturally occurring iridoid compounds. A sharp distinction between iridoids on one side and secoiridoids in the broader sense on the other side seems to be useful just in order to make working on this comprehensive group of natural compounds easier.

From the biosynthetic point of view (12), there exists a close relationship between these subgroups, as indicated by the co-occurrence of iridoid and secoiridoid glucosides like loganin (5) and sweroside (17) in Cornaceae, Dipsacaceae, and Loganiaceae (19-21) or loganin (5) and secologanin [loniceroside (7)] in Caprifoliaceae plants (22). 
This connection is formally confirmed by the occurrence of dimeric monoterpene glucosides such as cantleyoside (18) in Dipsacaceae (20) and Caprifoliaceae plants (23), containing each an iridoid and secoiridoid moiety linked by esterification. The biosynthetic interrelation between open-chain monoterpenes like geraniol/nerol and iridoids (loganin) as well as secoiridoids such as foliamenthin (19) had been recognised earlier by Battersby et al. (24) as well as Loew et al. $(25,26)$ in the course of their studies by feeding experiments on Menyanthes trifoliata.
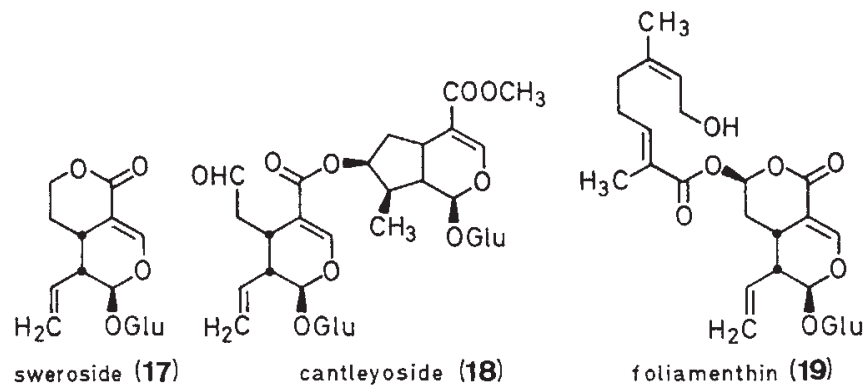

The intention of this survey is to point out developments in the fields of isolation and structure elucidation of iridoid compounds, giving only a selection from the huge amount of results recently reported.

\section{Isolation and Separation of Iridoids and Secoiridoids}

Iridoid glycosides as well as secoiridoid glucosides in general must be considered as potentially unstable natural compounds. If the sugar moiety is removed by enzymatic or acidic cleavage of glycosidic bonds the resulting aglycone often decomposes.

Iridoids belonging to the subgroup of the chromogenic glycosides, which mostly give blue-shaded colours under acidic conditions, were named "pseudoindicans" or "aucubin glucosides" (11). Considering the sensitivity of iridoids in the broader sense, isolation techniques must be as gentle as possible, omitting procedures which may modify or destroy genuine compounds. The various methods for the isolation of iridoid glycosides have been reviewed previously $(5,6)$. Among them are the charcoal method and the use of lead acetate as clarifying agent in order to preclean alcoholic extracts prior to separation by column chromatography on silica gel. Since polar compounds like iridoid glycosides might undergo irreversible adsorption to a greater or lesser degree during the course of these procedures, several new techniques have been evolved.

\section{Reversed-phase and countercurrent techniques}

For the large-scale, semi-preparative and analytical separations of polar compounds, various methods involving high-performance liquid chromatography (HPLC) have been developed which exclude the irreversible adsorption by the use of reversed-phase columns. Iridoid and secoiridoid glucosides have been separated on RP-8 and RP-18 columns in the analytical mode
(27-29) using a variable wave-length detector. In order to examine the homogeneity of the peaks, field desorption mass spectrometry and photodiode array detection have been applied $(30,31)$.

As alternatives to and modifications of the well-known countercurrent distribution technique according to Craig (32), RLCC (rotation locular countercurrent chromatography) (33) and DCCC (droplet countercurrent chromatography) (34) have been applied; these methods involve replacement of solid stationary phases by liquid mediums. In both cases, samples can be recovered quantitatively, since no solid packing material is present which might cause irreversible adsorption. RLCC and DCCC, therefore, have been used in the preparative separations of both secoiridoids and iridoids. The application of these techniques has not replaced the common chromatographic separation methods but, in general, they have been used as complements either alone or in combination with other methods as part of a complex isolation concept. The capability of DCCC, especially, in the separation of iridoids and secoiridoids was demonstrated by Chaudhuri et al. (35) for the separation of diastereoisomeric iridoid glucosides. Also, Hostettmann et al. (36) provided further evidence for the quality of DCCC separation when using it to isolate the bitter principles of some Gentiana species.

As a part of a combined application of gentle isolation techniques, however, DCCC has also been employed in order to prefractionate crude plant extracts. Then, final purification of the resulting fractions can be achieved by preparative or semi-preparative reversedphase HPLC using RP-8 or RP-18 columns (37). In order to separate aliphatic glycosides such as iridoids and secoiridoids from aromatic and/or phenolic compounds, a CC stage on Sephadex LH 20 may be inserted, thus providing a "gentle isolation concept" as elaborated by Gross (38), by replacing preparative HPLC with LPC (low pressure chromatography).

Preparative separations have also been carried out in order to separate typical Gentianaceae secoiridoids in the medium-pressure mode (MPLC) (39) using RP-8 material and giving rise to high resolutions in one step, comparable to those of analytical HPLC. Additionally, an HPLC method has been developed for the separation of a wide range of water-soluble glycosides using normal but slightly modified silica gel columns and water-containing solvent systems (40).

\section{Forced-flow chromatographic techniques}

Furthermore, the application of various planar chromatographic techniques for the separation of iridoid glycosides as well as secoiridoid glucosides has recently been described. Among these, forced-flow techniques like overpressure layer chromatography (OPLC) and ultra-micro-chamber centrifugal layer chromatography (UCLC) have been employed. Both methods have been used for the qualitative and quantitative analysis of eight iridoid glucosides from Veronica officinalis; best separations were obtained by linear OPLC on TLC and HPTLC plates. The circular UCLC technique may be preferred in case of chemotaxonomical studies if a large number of sam- 
ples must be analysed (41, and Refs. cited therein). Preparative on-line OPLC has been applied as a new and rapid isolation procedure for natural products (42) using the "PRISMA"-optimisation model (43) to optimise the mobile phase e.g. for separation of the four main bitter constituents of Gentiana purpurea. Using this procedure, scraping and eluting of bands is avoided, since the separated components are drained from the plate and collected. The methodology of preparative on-line OPLC may be simplified using onplate injection as a novel and rapid sample application technique (44).

\section{Structure Elucidation of Iridoid Glycosides and Secoiridoid Glucosides}

Up to 1978 (8), structural information on naturally occurring iridoid compounds was still obtained mainly by chemical correlation of new compounds with already known constituents and/or by using spectroscopic means such as UV, IR, and ${ }^{1} \mathrm{H}-\mathrm{NMR}$ spectroscopy as well as mass and ${ }^{13} \mathrm{C}$-NMR spectroscopy $(45-47)$ to a lesser extent. Chemical correlation implies the modification of compounds like iridoids and secoiridoids, due to their instability toward acids, ensuring successful degradation. In order to establish structural features such as the relative and actual positions of functional groups or stereochemistry following the classical strategies of structure elucidation, a sufficient quantity of each compound must be available.

If complex isolation techniques have been used, the real content of isolated constituents can be given only as an average. However, contents of main constituents have been found in a scale up to $3 \%$ of the dried plant material. In the course of biosynthetic or chemotaxonomic studies, minor compounds often are of great significance. Hence, more sensitive spectroscopic techniques are essential when only small amounts of plant material are available.

The rapid progress in NMR spectroscopy within the last ten years has resulted in the employment of several novel puls-sequences in accordance with the high resolution of modern spectrometers. Therefore, recent developments have made ${ }^{13} \mathrm{C}$-NMR spectroscopy, in particular, a most reliable tool for the structure elucidation of both iridoids and secoiridoids.

The exceptional variability of iridoid glycosides in contrast to secoiridoid glucosides is caused mainly by the intact cyclopenta[c]pyran skeleton in $c i s$ junction, and also by substitution with functional groups at the carbon atoms of the cyclopentane ring. Moreover, configurational changes and esterification of hydroxy group by various aliphatic and aromatic acids as well as the occasional occurrence of sugar moieties other than glucose contribute to the complexity of iridoid glycosides.

In secoiridoid glucosides, however, up to now only glucose has been found as the sugar moiety. The variability of the 7,8-seco-skeleton only increases if, e.g., lactone ring formation to compounds like sweroside (17) and foliamenthin (19) has taken place.

\section{Investigation of iridoid glycosides}

Several systematic studies on structure elucidation of iridoid glycosides have been presented on the basis of the ${ }^{1} \mathrm{H}$ - and ${ }^{13} \mathrm{C}$-NMR spectra, utilising especially the striking sensitivity of ${ }^{13} \mathrm{C}$-NMR chemical shifts to steric effects for distinguishing stereoisomers $(48-54)$. In general, the access to ${ }^{1} \mathrm{H}$ - and ${ }^{13} \mathrm{C}-\mathrm{NMR}$ data of iridoid glycosides allows the determination of the substitution pattern, but establishing the relative configuration, e.g. at the cyclopentane ring centres (carbons 6, 7, and 8), was at first difficult. This difficulty is caused by pseudorotation due to the flexibility of the ring. Therefore, coupling patterns of ${ }^{1} \mathrm{H}$ NMR spectra may only be useful when all coupling constants are available.

\section{${ }^{13} \mathrm{C}$-NMR Spectroscopy as a reliable tool in the examination of epimerism}

The examination of epimeric pairs of iridoid glycosides by ${ }^{13} \mathrm{C}-\mathrm{NMR}$ spectroscopy gave clear evidence that significant differences exist in the spectra of 6hydroxy and 8-hydroxy epimers such as ajugol/ myoporoside (20)/(21) $(50-52)$ and monotropein methyl ester/gardenoside $(22) /(23)(48,50)$, respectively. A comparison of the available pairs of C-6, C-7, and C-8 epimers in light of ${ }^{13} \mathrm{C}-{ }^{1} \mathrm{H}$ coupling constants from fully protoncoupled spectra and attendent examination of effects due to substitution at C-4 $(51,52)$ allows the assignment of the relative configurations at carbons 6 and 8 by spectroscopic means.
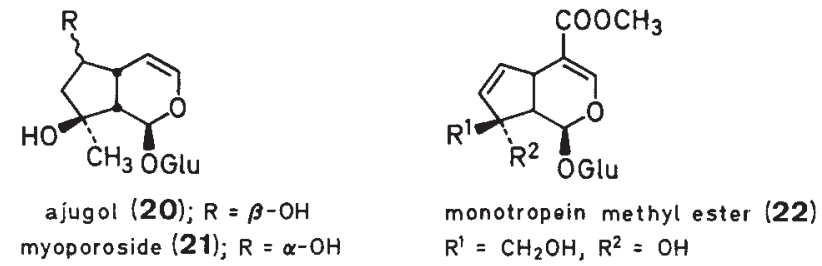

gardenoside (23); $\mathbf{R}^{1}=\mathrm{OH}, \mathrm{R}^{2}=\mathrm{CH}_{2} \mathrm{OH}$

\section{Effects of epimerism at carbon 6}

${ }^{13} \mathrm{C}$-NMR spectra of 6 - $O$-substituted epimeric pairs gave clear evidence that epimerisation at carbon 6 influences the ${ }^{13} \mathrm{C}$ chemical shifts of the $\beta$ - and $\gamma$ carbons 3 and 4 . When going from $\beta$ - to $\alpha$-hydroxy substitution, significant downfield (C-3) and upfield shifts (C-4) have been noted. Calculation of the shift difference between $\mathrm{C}-3$ and $\mathrm{C}-4$ led to the conclusion that this difference is consistently larger in all cases for 6 - $\alpha$-epimers than for the corresponding $\beta$-epimers. A systematic difference in coupling constants $\left(J_{\mathrm{C}-6, \mathrm{H}-6}, 6-\alpha-\mathrm{OH}>6-\beta-\mathrm{OH}\right)$ has also been noticed and may be a reliable criterion if spectra were obtained on high frequency spectrometers. Moreover, consistent downfield shifts of C- 1 of the iridene skeleton have been observed, a feature which may be useful in determining the configuration just for such compounds substituted at $\mathrm{C}-4$.

In further studies on C-6 epimers, Bianco et al. $(54,55)$ have considered close relationships between ${ }^{1} \mathrm{H}$ and ${ }^{13} \mathrm{C}$-NMR spectroscopy in the structure analysis of iridoids. Epimerism at C-6 has been shown to result in shift 
changes for $\mathrm{C}-1$ and $\mathrm{H}-1$. When going from $6-\alpha-\mathrm{OH}$ to $6-\beta-$ $\mathrm{OH}$ substitution, a shielding of $\mathrm{C}-1$ and a corresponding deshielding of $\mathrm{H}-1$ as well as a simultaneous change of the coupling constant $J_{\mathrm{H} 1,9}$ has been observed. On the basis of available NMR data, a direct proportionality between variations of $J_{\mathrm{H} 1,9}$ and $\Delta \delta \mathrm{C}-1$ as well as a direct relationship between $\Delta J_{\mathrm{H} 1,9}$ and $\Delta \delta \mathrm{H}-1$ has been demonstrated (55). Two different equations were given for $\mathrm{C}-6$ epimers characterised by a rigid cyclopentane ring (double bond or epoxy group) $(24,25)$ on one side and a second for such compounds having a saturated cyclopentane ring $(26,27)$ on the other side. Taking into account that $J_{\mathrm{H} 1,9}$ is larger for $6-\alpha$ hydroxy epimers in all available pairs, the resulting two formulae may also be useful in the structure elucidation of iridoidic compounds.

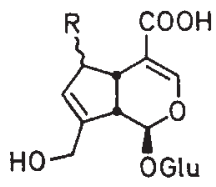

scandoside (24); $R=\beta-O H$

10 -deacetylasperulosidic acid (25)

$\mathrm{R}=\boldsymbol{\alpha}-\mathrm{OH}$

Finally, it should be noticed that the cause of variations in chemical shifts and coupling constants involving $\mathrm{C}-1$ have been discussed by Damtoft et al. (51) as well as Bianco et al. (55) from different points of view. Thus, the large shift difference observed for $\mathrm{C}-1$, when comparing $\alpha$ - and $\beta$-series, combined with the change in the coupling constant $J_{1,9}$ indicates fundamental changes in the conformation of the whole molecule. The change seen for $J_{1,9}$ may be explained by a "flip-over" of the dihydropyran ring, in agreement with the large differences for carbons 1,3 , and 4 in the ${ }^{13} \mathrm{C}$-NMR spectra of C- 6 epimers, but inconsistent with the minimal changes observed for carbons 5 and 9. The changes of the ${ }^{13} \mathrm{C}$ chemical shifts of the C-6 epimers may be explained further by cis/trans-interactions using cis/trans disubstituted cyclopentanes as model compounds, taken into account that the C-5 shifts do not conform to this view (51). In contrast to iridoids having a saturated cyclopentane ring and lacking $\mathrm{C}-5$ substituents, C-6 epimerism effects on $\delta \mathrm{C}-5$ are present in couples having a $\Delta^{7}$-double bond. Therefore, it is concluded that a greater conformational mobility, present in constituents with a saturated cyclopentane ring, counteracts the effects of the interaction between the hydroxy group at C-6 and the C-4/ C-5 bond (55).

\section{Effects of epimerism at carbon 7}

Pairs of $\mathrm{C}-7$ epimers are very rare and, therefore, only few NMR data are available up to now. As the centre of epimerism is far removed from the carbons involved in ring junction, the use of methylcyclopentanols as model compounds is undisputed $(51,55)$. According to the trans-relationship between $7-\alpha-\mathrm{OH}$ and $8-\beta-\mathrm{CH}_{3}$ of $7-$ epiloganin (28) in comparison with loganin (5) deshielding has been observed for resonances of carbons analogous to those of the pair of trans/cis-methylcyclopentanols (56).<smiles>CC(=O)C1=CO[C@@H](O[Ga])[C@@H]2[C@@H]1C[C@@H](O)[C@@H]2C</smiles>

\section{Effects of epimerism at carbon 8}

The effects of epimerism on carbon 8 of the iridene skeleton are completely pointed out and discussed in Refs. $(51,52$, and 55). On the basis of different substitution patterns, $\mathrm{C}-8$ epimers have been subdivided into three groups. Epimerism effects observed in the ${ }^{13} \mathrm{C}$-NMR spectra are similar in all available epimers as far as carbons 9 and 10 are concerned. However, shifts of carbons 1 and 8 remained almost unchanged and therefore the usefulness of methylcyclopentanols as models needs to be considered again. In contrast to cyclopentanols composed of different amounts of conformational isomers, the situation in the iridene skeleton must be different when considering the presence of the bicyclic system and the influence of the sugar moiety (55).

In $\mathrm{C}-8$ epimers not $O$-substituted at $\mathrm{C}-7$ or C-8 [e.g. stansioside (29)/plantarenaloside (30)] (57) as well as those $O$-substituted at $\mathrm{C}_{-}-7$, but not at C-8 [e.g. loganin (5)/ 8-epiloganin (31)], significant upfield shifts are observed for $\mathrm{C}-9$ and $\mathrm{C}-10$ when going from $8 \beta$ - to $8 \alpha$-epimers. For this reason, a distinction between the $8 \alpha-(\delta \mathrm{C}-10<17 \mathrm{ppm})$ and $8 \beta$-series $(\delta \mathrm{C}-10>18 \mathrm{ppm})$ can be made, as was pointed out by Damtoft et al. (51).
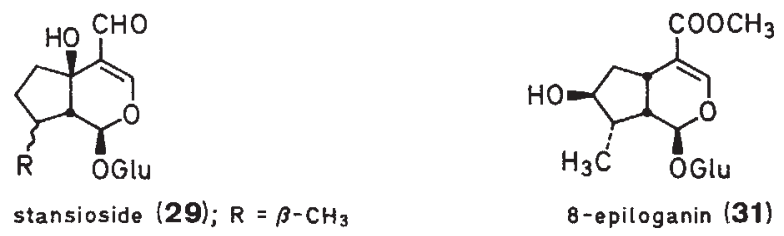

stansioside (29); $R=\beta-\mathrm{CH}_{3}$ plantarenaloside $(30) ; \mathrm{R}=\alpha-\mathrm{CH}_{3}$

The large downfield shift of C-9 in C-8 epimers $O$-substituted at $\mathrm{C}-8$, first observed by Chaudhuri et al. (50) in the spectra of monotropein methyl ester (22) and gardenoside (23) when going from 22 to 23 , has been shown to be a general effect. However, this effect is opposite to the one in epimeric pairs not substituted by an 8-hydroxy group.

On the basis of the numerical dependency of the chemical shift for C-9 of the iridoid skeleton on the stereochemistry at C-8, determination of the configuration at this centre by using shift increments for each substituent in a shift calculation of $\mathrm{C}-9$ is possible in a wide range of iridoidic compounds. In order to allow an extensive application of the shift calculation, solvent effects were omitted on comparing spectra of iridoids recorded in $\mathrm{D}_{2} \mathrm{O}$ and $d_{4^{-}}$ $\mathrm{MeOH}$ with regard to the ${ }^{13} \mathrm{C}$ chemical shift of $\mathrm{C}-9(51)$.

In addition to the determination of the stereochemistry at C-8 by increments, further uses of increment sets in the structure elucidation of iridoids have been 
reported. Sets of increments are obtained if the effect of one single substituent is determined by subtracting the shift values of two known compounds which are identical in all structural features except for the respective substituent [e.g., values of dihydrocornin (32) and deoxyloganin (33)]. The resulting increment set for the 6 - $\beta$-hydroxy group can be inserted by addition to the ${ }^{13} \mathrm{C}$-NMR spectrum of, e.g., the known compound splendoside (34) to obtain a "synthetic spectrum" of 6- $\beta$-hydroxysplendoside (35) in sufficient agreement with the recorded spectrum of this compound. This procedure is limited by cis/trans-interactions of vicinal substituents which override the effects of single substituents $(51,58)$.

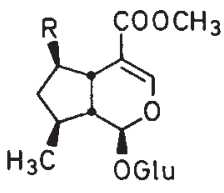

dihydrocornin (32); $\mathrm{R}=\mathrm{OH}$ deoxyloganin (33); $\mathrm{R}=\mathrm{H}$

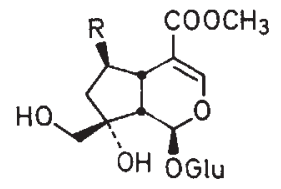

splendoside $(34) ; \mathrm{R}=\mathrm{H}$

6 - $\beta$-hydroxysplendoside $(35) ; R=O H$

\section{Assignment of the configuration at carbon 1 of sugar moieties}

In order to assign the configuration at $\mathrm{C}-1$ ', that means the anomeric carbon of the sugar moiety of iridoid glycosides and secoiridoid glucosides, protoncoupled ${ }^{13} \mathrm{C}$-NMR spectra of a number of hexopyranoses are available. When going from the $\alpha$-anomers to the $\beta$-anomers, a decrease in the magnitude of the ${ }^{13} \mathrm{C}, \mathrm{H}$ coupling constant is observed. The difference of approx. $10 \mathrm{~Hz}$ in all investigated anomeric pairs is a general value, thus allowing one to determine the configuration at the anomeric centre (59).

\section{Acylation patterns of valepotriates}

A very special problem arises from a structural feature of the non-glycosidic valepotriates such as valtrate (6) in so far as the locations of different acyloxy substituents must be determined. The characteristic dependence of the ${ }^{13} \mathrm{C}$-NMR shifts on the type and the position of the substituents allows unequivocal assignments (60).

\section{Developments in NMR spectroscopy employed in structure elucidation}

In order to assign ${ }^{13} \mathrm{C}$ chemical shifts, besides PND (proton noise decoupled) and full coupled spectra, frequently SFORD (single frequency off-resonance proton decoupled) spectra have been employed. Thus, part of the coupling information can be retrieved for the assignment of resonances to methyl, methylene, methine, and quaternary carbon sites. However, the off-resonance experiment is not completely satisfactory if signals appear as ill-defined multiplets. Overlapping of resonance lines and changes of ${ }^{13} \mathrm{C}$ shieldings due to temperature effects may also limit the value of off-resonance spectra, especially if the region of interest contains a number of resonances. Finally, this technique is time-consuming and less sensitive when compared with the PND techniques. In the course of studies on iridoids and other constituents from Penstemon species
$(61,62)$, the SEFT (spin echo fourier transform) experiment $(63,64)$ has been applied, allowing one to distinguish and to assign carbons with a sensitivity similar to that of PND spectra.

In addition, 2D, C,H correlation techniques were developed which facilitate the immediate correlation of ${ }^{13} \mathrm{C}$ - and ${ }^{1} \mathrm{H}$-NMR spectra displaying cross peaks for proton-carbon connectivities in a contour-plot diagram. These methods are well documented by several reviews $(65-67)$. A serious disadvantage of these methods is the relative insensitivity. Therefore, series of typically $128{ }^{13} \mathrm{C}-\mathrm{NMR}$ spectra must be recorded to obtain the required information. Thus, recording spectra of rare compounds available only in small quantities is extremely time-consuming or even impossible. To resolve these problems, the inverse $2 \mathrm{D}$ $\mathrm{C}, \mathrm{H}$ correlation may be employed; this was reported by $\mathrm{Bax}$ et al. (68) as well as Berger et al. (69) using a novel sensitive puls sequence to obtain complete $\mathrm{C}, \mathrm{H}$ correlations of only a few milligrams of sample and consuming only a few hours of spectrometer time. This technique was recently applied to the elucidation of some unsolved structural features of dihydrofoliamenthin (41) (70).

It should be mentioned that developments in ${ }^{1} \mathrm{H}$-NMR spectroscopy are no less impressive than in ${ }^{13} \mathrm{C}$ NMR since superconducting magnets have made proton resonance frequencies of 300 and $400 \mathrm{MHz}$ commonplace. The greater field strength increases chemical shifts, thereby reducing the chance of overlap of spectral multiplets. In addition, the 2D NMR experiment, called homonuclear correlation spectroscopy (COSY or HOMCOR), can replace a large number of homonuclear decoupling experiments by displaying all of the proton-proton spin couplings on one 2D plot.

Proton homonuclear 2D-J-correlated NMR spectra in the field of iridoid glycosides have been used to give more unequivocal results in the interpretation of proton spectra of constituents like 10-methylixoside (36) (71) or valeriana-type ester iridoid glycosides like ebuloside (37) or $6^{\prime}-O$-apiosylebuloside $(\mathbf{3 8})(72,73)$.

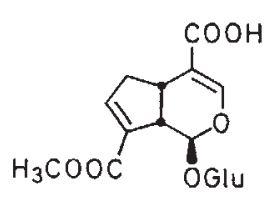

10-methylixoside (36)
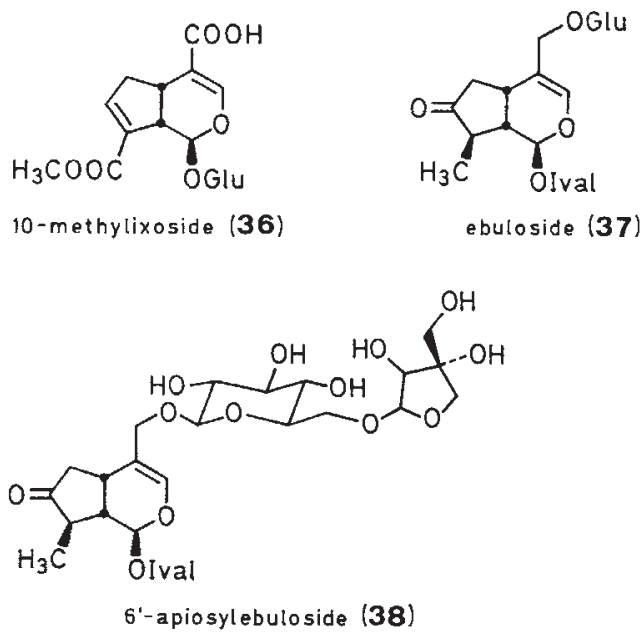
Moreover, in order to verify assumed structures in several instances, NOE (nuclear Overhauser enhancement) spectroscopy has been applied in different modes $(74-76)$. NOE is a powerful tool for structure and conformation determinaiton as the enhancements are inversely related to the sixth power of the interproton distance. Using NOE spectroscopy, it is possible to determine the relative configurations of $\mathrm{C}-8$ epimeric pairs of iridoid glycosides such as pulchelloside I and II (39/40) (77) when a fixed conformation of the cyclopentane ring is assured by acetonide formation. In some other studies, proposed structures of iridoid glycosides without fixed conformations of the cyclopentane ring were confirmed by using NOE difference spectroscopy as well as 2D NOESY and selective hetero ${ }^{1} \mathrm{H},{ }^{13} \mathrm{C}$ NOE difference NMR spectroscopy $(38,61,71,78-$ $82)$.

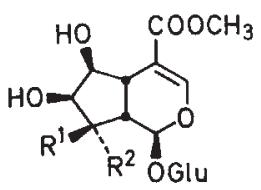

pulchelloside I (39); $\mathrm{R}^{1}=\mathrm{H}, \mathrm{R}^{2}=\mathrm{CH}_{3}$ pulchelloside II (40); $\mathrm{R}^{1}=\mathrm{CH}_{3}, \mathrm{R}^{2}=\mathrm{H}$

The problem already mentioned concerning the pattern of acyloxy substituents in the field of nonglycosidic iridoids of valeriana-type (see above) can also been resolved with the help of ${ }^{1} \mathrm{H}$-lanthanide-induced shifts (83) or chemical ionisation mass spectrometry (CI-MS) (84).

\section{Mass spectrometry of iridoids and secoiridoids}

Mass spectrometry has always been used in iridoid as well as secoiridoid investigations up to now. However, the structural properties and the sensitivity of these constituents frequently led to thermal decomposition caused by the higher temperatures needed for evaporation when using the EI technique. The mass spectrometry of iridoids has been reviewed by Popov et al. (85) discussing the usefulness of several other ionisation techniques such as $\mathrm{CI}$ (chemical ionisation), FD (field desorption), and NI (negative ionisation). In general, structural information according to substitution of the aglycone moiety pattern, presence of double bonds, type and location of acyloxy substituents - but no molecular ion peak - can be obtained by EI-MS of underivatised iridoids. Molecular ions may only be detected if derivatisation, e.g. acetylation, has been employed.

The new ionisation techniques mentioned above are capable of providing spectra of non-volatile and/ or thermolabile compounds without derivatisation. Thus, they represent an important development for the identification of polar natural constituents. A soft ionisation method like FD-MS is a well established technique for the analysis of iridoid glycosides and secoiridoid glucosides and generally provides molecular or pseudomolecular ions but with only few other significant fragments such as the aglycone and the sugar moiety. This technique in general is applied if structures derived by NMR data need to be confirmed by mass spectral data. Therefore, the published data mostly consist of only pseudomolecular ions like $[\mathrm{M}+\mathrm{H}]^{+}$or $[\mathrm{M}+$ $\mathrm{Na}]^{+}$.

$\mathrm{CI}$ and desorption/chemical ionisation (D/ CI) are soft techniques and allow one to obtain molecular or pseudomolecular ions as well as typical fragmentation patterns. When compared with FD-MS, the employed CI techniques show better reproducibility (86).

In recent times $\mathrm{FAB}$ (fast-atom bombardment) mass spectrometry has been developed and attained widespread use because of several important advantages: Ions can be generated from samples at room temperature; the spectra contain both molecular mass and fragmentation information. Data are usually obtained from $[\mathrm{M}+\mathrm{H}]^{+}$ions and $[\mathrm{M}-\mathrm{H}]^{-}$ions in positive and negative ion spectra, respectively (87). The application of FAB mass spectrometry in the course of structure elucidation of iridoids was reported for several different compounds (38, 71, 88-93). The negative ion mass spectroscopy has been reported to be useful in the structure elucidation of iridoids from Verbascum species (94).

Permethylated iridoids have been analysed by GC/MS in order to investigate a great number of plant species in the course of chemotaxonomic studies (81).

\section{Investigation of secoiridoid glucosides}

The structures of simple secoiridoids of the secologanin-type can easily be derived from NMR data. Clear ${ }^{13} \mathrm{C}-\mathrm{NMR}$ spectra and characteristic signal patterns of substituents of the dihydropyran ring, e.g. vinylic groups, are obtained from ${ }^{1} \mathrm{H}$-NMR spectra. But, as mentioned above, a more demanding situation arises if additional ring formation has taken place in the molecule.

The variability of secoiridoid glucosides therefore increases if lactone ring or tetrahydropyran ring as well as tetrahydropyrone ring formation has occurred. These structural features have been observed in several compounds, e.g. sweroside (17)/dihydrofoliamenthin (41), secogalioside (42)/morroniside (43), and hydrangenosides like (44). Further variability is caused by asymmetric centres always involving C-7 and occasionally C-8 of the secoiridoid skeleton.

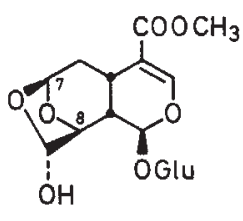

secogalioside (42) morroniside (43)<smiles>COC(=O)C1CC(O)OC(C)C1C(O)O</smiles>

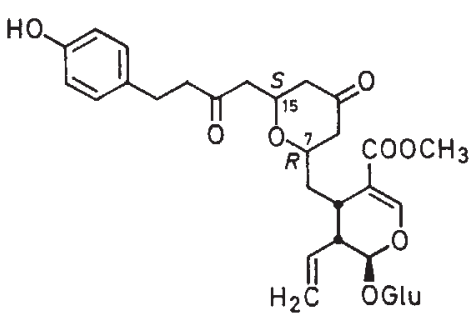


As a result of the always different structural features, no general strategy for the structure elucidation can be given like that available for iridoid glycosides. However, early systematic studies were reported by Cornelis et al. (95) and Bock et al. (96). The structure of secogalioside (42), for example, was assigned by chemical correlation with sweroside (17) using ${ }^{1} \mathrm{H}$ - and ${ }^{13} \mathrm{C}$-NMR data as well as NOE experiments, thus allowing the full structure determination including conformation as well as the absolute configuration (96). Furthermore, it has been shown that compounds like morroniside (43) exist as a mixture of C-7 anomers in solution leading to mutarotational equilibrium. The lactone ring of dihydrofoliamenthin (41) exists in the chair conformation, as was confirmed by NMR data. Therefore, the $\beta$-position of the acyl group at C-7 can be deduced from by a complete set of coupling constants (70).

The structures of the hydrangenosides such as 44 (97), characterized by increased complexity, were established by spectroscopic means including NOE experiments. Comparison with similar synthetic model compounds allowed the determination of the configuration at all asymmetric centres.

\section{New Types of Iridoids and Secoiridoids}

Developments in the fields of isolation and structure elucidation referred to above led to the identification of several novel types of iridoids as well as secoiridoids. The range of naturally occurring iridoid compounds therefore may be expanded by the following types.

\section{Iridoids with a 9 carbon atom basic skeleton}

Cistanin (45) and cistachlorin (46) are nonglycosidic constituents of Cistanche salsa (Orobanchaceae) (98), lacking the enol ether bond but possessing an ether structure linking carbons 1 and 10. A remarkable structural feature of 46 is a 7-chloro substituent. The non-glycosidic iridoids rehmaglutin B (47) and C (48) were isolated from Rehmannia glutinosa (Scrophulariaceae) (99), the former
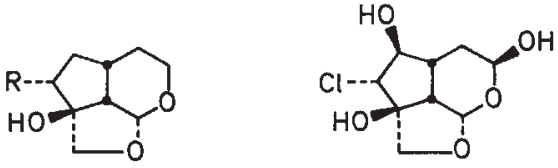

cistanin (45); $R=O H \quad$ rehmaglutin $B(47)$

cistachlorin (46); $\mathrm{R}=\mathrm{Cl}$

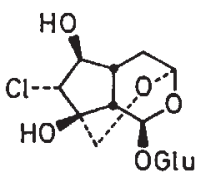<smiles>CO[C@@H]1C[C@@H]2C(COC(=O)c3ccc(O)cc3)=C[C@H](O)[C@@H]2[C@H](O)C1</smiles>

glutinoside (49)

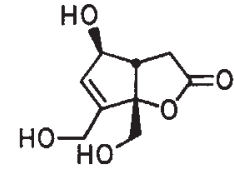

rehmaglutin C (48) lacking the enol ether double bond but being tricyclic and with a 7 -chloro substituent and two acetal functions, the latter unusually linked by formation of a five-membered lactone ring. The glucoside glutinoside (49) from the same source shows similar features as $\mathbf{4 7}$ and again has two acetal moieties. Nishindaside (50), isolated from Vitex negundo (Verbenaceae) (100), is a bicyclic compound with again two acetal groups. In addition, the cyclopentanoid tetrol derivatives eucommioside I (2"- $\beta$-D-glucopyranosyleucommiol; 51) and eucommioside II (1-O- $\beta$-Dglucopyranosyleucommiol; 52) have been isolated from Eucommia ulmoides (Eucommiaceae) and Aucubajaponica (Cornaceae) $(101,102)$, respectively.

\section{Iridoids with a 10 carbon atom basic skeleton}

Monocyclic iridodial-type constituents like iridodial-gentiobioside (53) and nepetariaside (54) have been recognised in Actinidia polygama (Actinidiaceae) and Nepeta cataria (Lamiaceae) $(103,104)$. Cerbinal (55) is a pseudoazulene-type iridoid and constituent of Gardenia jasminoides (Rubiaceae) (105). Non-glycosidic iridane-type lactones have been isolated from the volatile oil of Actinidia polygama (106), among them the new saturated five-membered actinidialactones $a(56)$ and $b(57)$. Further lactonetype compounds are gibboside (58) and nepetaside (59), constituents of Patrinia gibbosa (Valerianaceae) and Nepeta cataria $(107,108)$, having a D-glucopyranosyloxy group at C-7 of the iridane skeleton. Villosolside, a similar constituent of Patrinia villosa bears a $\mathrm{D}$-glucose moiety in a glycosidic linkage to a hydroxy group at C-8 (109).

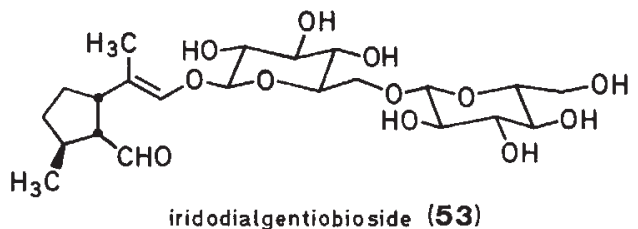

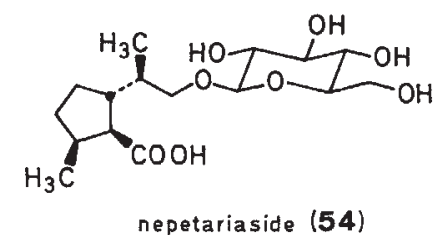<smiles>COC(=O)c1cocc2c(C)ccc1-2</smiles><smiles>[R]C1([R])C(=O)OC2(C)CC=C(C)C21[Y]</smiles>

actinidialactone a (56) $R^{2}=H, R^{2}=\mathrm{CH}_{3}$ actinidialactone b (57) $\mathrm{R}^{1}=\mathrm{CH}_{3}, \mathrm{R}^{2}=\mathrm{H}$

The iridoid glucoside pinifolin (60), isolated eucommioside 1 (51) $R^{1}=H, R^{2}=G l u$ eucommioside II (52) $R^{1}=$ Glu, $R^{2}=H$ from Penstemon pinifolius (Scrophulariaceae) (110), is characterised by two acetal groups and an unusual $\Delta^{3}$-double bond. Semperoside (61) and gelsemide 7-glucoside (62) from Gelsemium sempervirens (Loganiaceae) (111) show

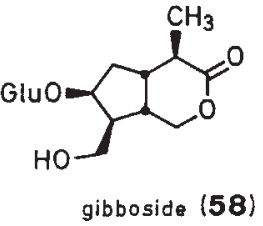<smiles>CO[C@H]1C[C@@H](C)[C@@H]2C(=O)OC[C@H](OC)[C@H]12</smiles> 
structural features similar to asperuloside but lack either the enol ether double bond or the acetal function. The glucose moiety is linked to C-3 and C-7, respectively. In addition, 62 is one of the first regular iridoids hydroxylated at C9. Verbraside is a highly hydroxylated compound from Verbena brasiliensis (Verbenaceae), resembling semperoside in all characteristic structural features (112).<smiles>CC1CCC2=C(C=O)[C@H](O)O[C@H](O)[C@H]21</smiles>

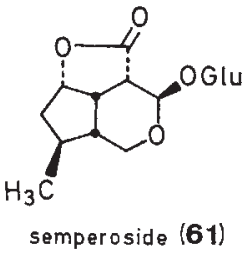

\section{Secoiridoids}

A non-glycosidic secoridoid-type compound called methyl syramuraldehydate (63) was isolated from Syringa amurensis (Oleaceae) (113). The first two secoiridoid glucosides of the valeriana-type (that means glucose attached to C-11), isosweroside (64) and secoebuloside (65) were isolated from Sambucus ebulus (CaprifoliaceaeSambucaceae) $(114,38)$.<smiles>CC(=O)CC1C(C(=O)O)=COC(C)[C@@H]1C</smiles>

methyl syramuraldehyde (63)

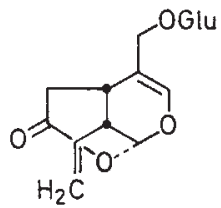

(64)

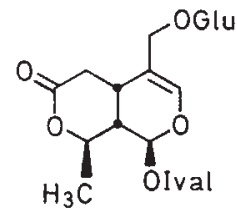

(65)

\section{Dimeric iridoids}

Compounds like urceolatoside B (66), linked by esterification (C-7 to C-11") are constituents of Viburnum urceolatum (Caprifoliaceae-Viburnaceae) (115). Argylioside (67) and radiatosides are constituents of $\mathrm{Ar}$ gylia radiata (Bignoniaceae) (116-118), linked by esterification (C-6 to $\left.\mathrm{C}-11^{\prime \prime}\right)$.

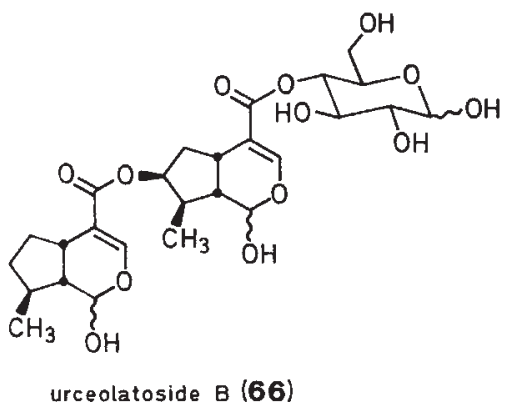

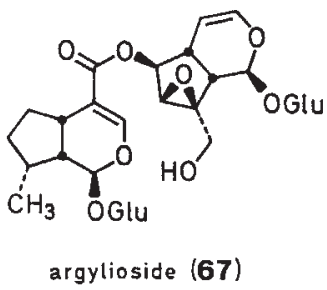

\section{Bisglycosidic iridoids and secoiridoids}

Iridoid-secoiridoid congeners like abeliosides a (68) and b are constituents of Abelia grandiflora (Caprifoliaceae). These compounds each consist of one secoiridoid unit and an iridoid lactone with a C-9 skeleton linked by esterification (119).<smiles>C=CC1C(OC)OC=C(C(=O)OC2CC3COC(=O)CC3C2C)C1CCO</smiles>

abelioside a $(68)$

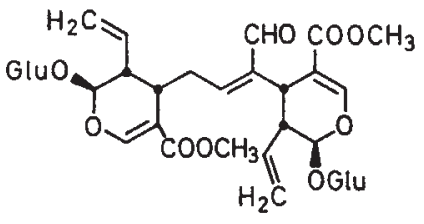

centauroside $(\mathbf{6 9})$

\section{Dimeric secoiridoids}

Centauroside (69), isolated from Erythraea centaurium (Gentianaceae) (120) is the first pure bis-secoiridoid linked by a C-C bond.

\section{Iridoids conjugated with monoterpene units}

Amareloside (70) is the first constituent of this type, isolated from Tecoma chrysantha (Bignoniaceae) (121), consisting of a 6-epiaucubin unit linked to a geranioltype monoterpene acid by esterification. Nemoroside and nemorososide from Penstemon nemorosus (Scrophulariaceae) (122) as well as 8-O-foliamethoyleuphroside from Clerodendron incisum (Verbenaceae) (82) are similar compounds. Kickxioside from Kickxia spuria (Scrophulariaceae) (123) is a very similar congener of menthiafolic acid and antirrhinoside.<smiles>CO[C@H]1OC=CC2C(OC(=O)/C(C)=C/CC/C(C)=C/CO)=CC(CO)[C@@H]21</smiles>

\section{Complex iridoids and secoiridoids}

$2^{\prime}-O, 8$-O-Dihydrofoliamenthoyleuphroside (71) (82) consists of an iridoid moiety and two geraniol-type acids. Jasmoside (72), isolated from Jasminum mesnyi (Oleaceae) (124), contains two secoiridoid glucoside moieties linked together by a cyclopentanoid monoterpene unit in esterification. Sambacolignoside (73), a constituent of Jasminum sambac (Oleaceae) (125), is composed of a secoiridoid part and a lignane glucoside moiety. Desfontainic acid (74) and its acyl glucoside are the first secoiridoidtriterpenoid congeners, isolated from Desfontainia spinosa (21). Finally, complex secoiridoid glucosides like oleonuzhenide (75) have been observed to occur in Ligustrum japonicum (Oleaceae). These compounds may be considered as dimeric secoiridoids, linked to a $p$-hydroxyphenylethyl-glucosyl unit by esterification (126). 


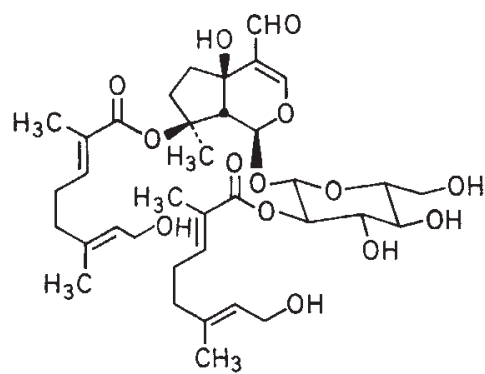

$2^{2}-0,8-0$-difoliamenthoyleuphroside (71)

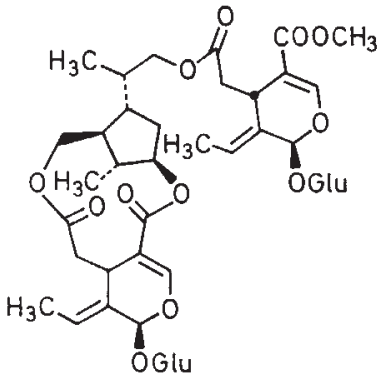

jasmoside (72)

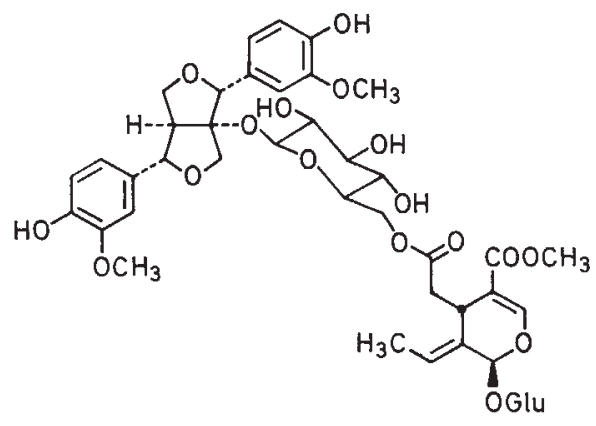

sambacolignoside (73)

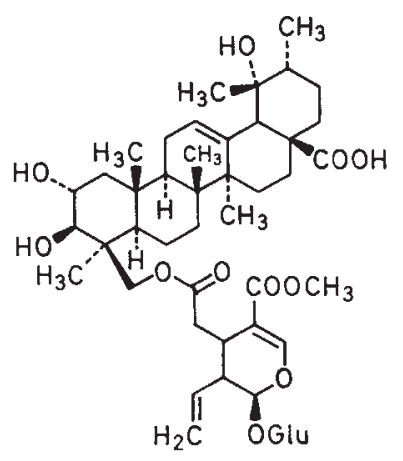

desfontainic acid (74)

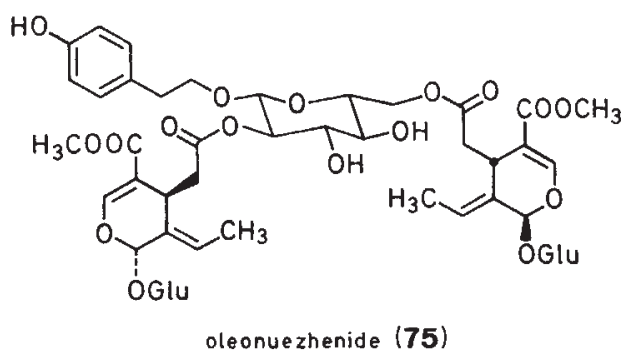

\section{New Carbohydrate Moieties of Iridoid Glycosides}

Besides the remarkable variability of the iridane skeleton referred to before, it should be pointed out that in addition to sugar moieties already known to be constituents of iridoid glycosides, some further mono- and disaccharides have been encountered. Surprisingly, some of the rare monosaccharides were observed to occur only in valeriana-type iridoid glycosides up to now, characterised by linkage of carbohydrate moieties to $\mathrm{C}-11$ and an isovaleroyl group attached to $\mathrm{C}-1$ of the corresponding aglycone.
Apiose has been confirmed to be the outer sugar moiety of the disaccharide unit of $6^{\prime}-0$ apiosylebuloside (38) (73), linked to C-6 of the inner glucose unit. 3-Keto-glucose was found to occur as the sole sugar moiety of serruloside (76) and dihydroserruloside, both constituents of Penstemon species (Scrophulariaceae) (90, 127). Moreover, the two further iridoids serrulatoside (77) and penstemideaglucone-11-O- $\beta-4^{\prime}$-deoxymannopyranosido- $6^{\prime}-O-\beta_{\mathrm{D}}$-glucopyranoside (78) were confirmed to contain disaccharide units consisting of 4-deoxyaltroseglucose and 4-deoxymannose-glucose, respectively. In both cases the outer glucose moiety is linked to C-6 of the inner 4-deoxyhexose $(62,90,127)$. From Odontites verna ssp. serotina (Scrophulariaceae) aucubigenin-1-O- $\beta$-serotinoside (79) has been recognised to contain a disaccharide consisting of an $\alpha$-D-xylopyranose moiety attached to C- 6 of the inner glucose unit (128). Moreover, aucubigenin-1- $O-\beta$ cellobioside has been isolated from the same source (129). The disaccharide cellobioside is also present as the sugar moiety of penstebioside, a constituent of Penstemon richardsonii (90).<smiles>O=C1C(O)C(CO)C(O)C(O)C1OCC1=COC(O)C2C(CO)=CCC12</smiles>

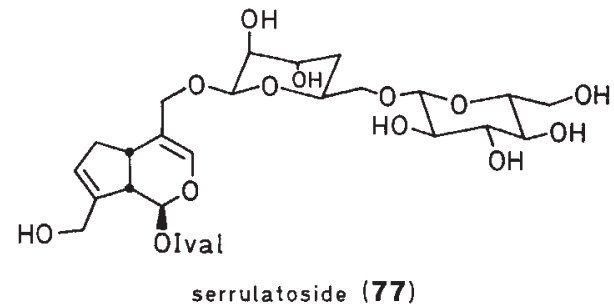

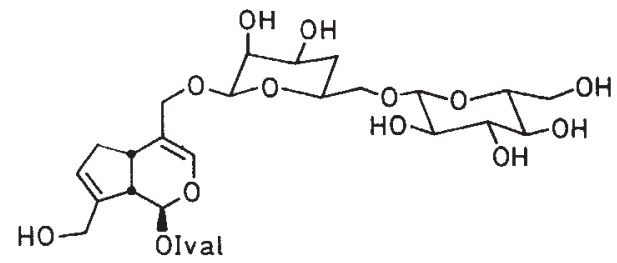

penstemideaglucone-11-0- $\beta-4^{\prime}-$ deoxymannopyranosido-6'-O- $\beta$-D-glucopyranoside $(78)$

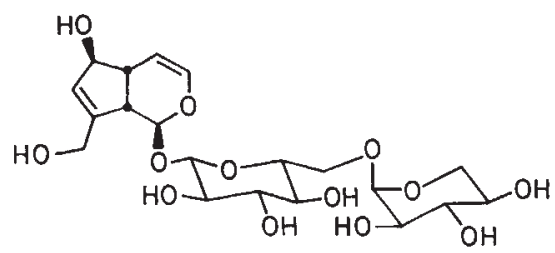

aucubigenin-1- $\beta$-serotinoside (79) 


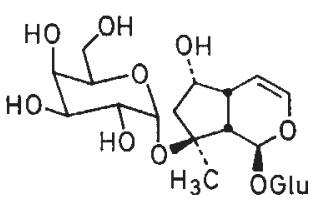

rehmannioside $\mathrm{C}(\mathbf{8 0})$

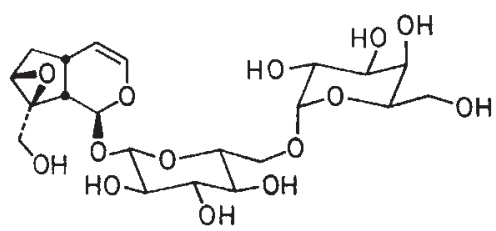

rehmannioside $A(\mathbf{8 1})$

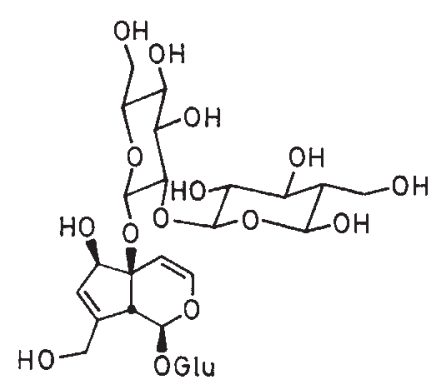

rehmannioside D (82)

Further novel iridoid glycosides containing mono- and disaccharides were identified from Rehmannia glutinosa (Scrophulariaceae) (130). Rehmannioside C (80) was identified as 8-O- $\alpha$-D-galactopyranosylleonuride, the structures of rehmannioside $A$ and $D$ were established to be $6^{\prime}-O$ - $\alpha$-D-galactopyranosylcatalpol $(\mathbf{8 1}$; = catalpolgenin- $\beta$ melibioside) and sophorosyl-monomelittoside (82), respectively.

\section{Novel Acylation Patterns}

The huge number of naturally occurring iridoid compounds is further caused by the variability of the acylation pattern. When considering that hydroxy groups either linked to the basic skeleton or to the carbohydrate moiety may be involved in esterification, a subdivision into these two groups seems to be reasonable.

\section{Acylation of hydroxy groups linked to the basic skeleton}

From Linaria clementei (Scrophulariaceae) (131) the two ester iridoid glucosides 6-senecioylantirrhinoside (83) and 6-angeloylantirrhinoside (84) were isolated. 6-Isovanillylcatalpol (85) has been detected in Castilleja liniariffolia (Scrophulariaceae) (132). The acyl substituents have been encountered for the first time as constituents of ester iridoids. Senburiside II (86), a constituent of Swertia japonica (Gentianaceae), was elucidated to be 7 epi-(di-m-hydroxybenzoyl)-loganic acid (133), whereas periclymenoside (87) was shown to consist of loganin and 4-O-( $\beta$-D-glucopyranosyl)-trans-ferulic acid (134).

Allaneroside (88) is a plumieride-type compound, isolated from Allamanda neriifolia (Apocynaceae), and has been characterised as $13-O$ - $(\beta$-hydroxyphenyl)- $\beta$ hydroxypropionyl plumieride (135). Jasminoside (89), isolated from Jasminum humile, is the first example of secoiridoid glucosides belonging to the 10-hydroxyoleoside series, in which the C-10 hydroxy group is esterified by trans-cinnamic acid (136).
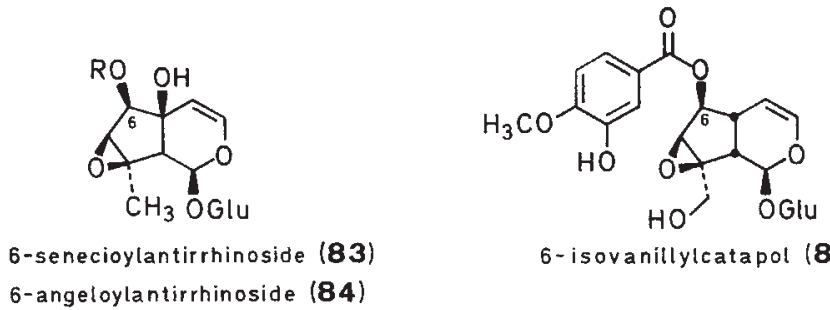

6-angeloylantirrhinoside (84)

6-isovanillylcatapol (85)<smiles>CO[C@H]1OC=C(C(=O)O)C2CC(OC(=O)c3cccc(Oc4cccc(O)c4)c3)[C@H](C)[C@@H]21</smiles>

senburiside II (86)

periclymenoside (87) (c)

allaneroside $(\mathbf{8 8})$<smiles>COC(=O)C1=CO[C@H](OC)[C@@H]2C1C[C@H](OC(=O)/C=C/c1ccc(OC)c(OC)c1)[C@H]2C</smiles>

\section{Acylation of hydroxy groups linked to the carbohydrate moiety}

Iridoid glycosides and secoiridoid glucosides are known to be esterified via involvement of the hydroxy groups attached to C-2/3 and C-6 and to C-2 as well as C-2/3/4/6 of the carbohydrate moieties (137-140), respectively. Novel iridoid glycosides esterified at C-2 of the carbohydrate unit have been isolated from several sources. Senburiside I (90) from Swertia japonica (Gentianaceae) was elucidated to be 7-epi-(m-hydroxybenzoyl)-2'sinapoylloganic acid, containing a novel sinapoyl moiety linked by esterification (141). From Gentiana pedicellata, e.g., $2^{\prime}$-cis/trans-feruloylloganin was isolated (88). Nigrosides 1 (91) and 2(92), constituents of Verbascum nigrum (Scrophulariaceae), were shown to be 6-O- $\alpha$-L-rhamnopyranosyl- $3^{\prime \prime}$-cinnamoylaucubin and 6-O- $\alpha$-L-rhamnopyranosyl-2"-cinnamoylaucubin (142), respectively. Undulatin from Tecomella undulata (Bignoniaceae) (143) and $4^{\prime}$-p-coumaroylloganin (93), isolated from Gentiana pedicellata (144), are simple iridoid glucosides both acylated at $C_{-}-4$ of the glucose moiety. Decentapicrin A (94) and $B(95)$ have been shown to be secoiridoid glucosides from Centaurium littorale (Gentianaceae), singly acylated at hydroxy groups at C-3' and C-4' of the sweroside unit (145). Finally, the ester iridoid glucoside depressoside (96), a constituent of Gentiana depress $a$, is characterised as 7-[6-(2,3dihydroxybenzoyl)-1-O- $\beta$-D-glucosyl $]-11-(1-O$-pyrogallyl)loganate (146). 


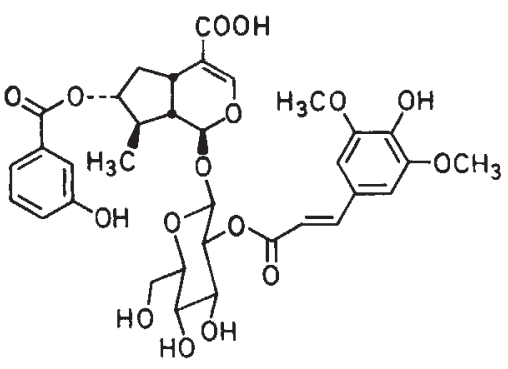

senburiside I $(90)$

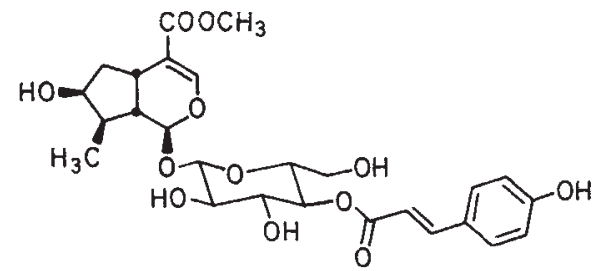

$4^{-}-p^{-}$-coumaroylloganin (93)
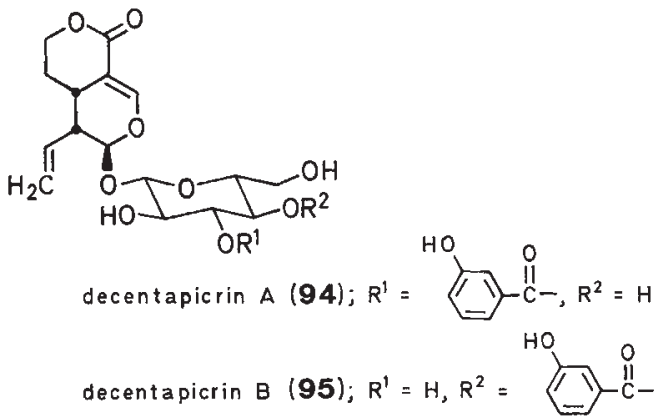

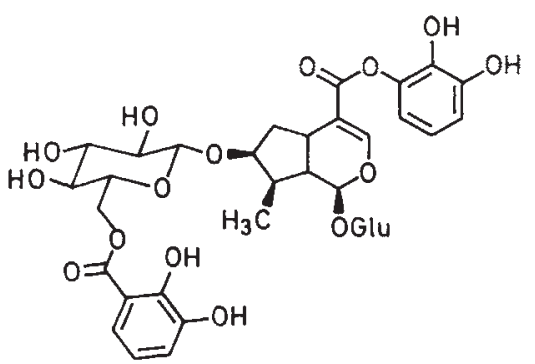

depressoside

96)

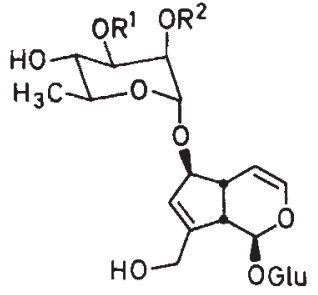

nigroside 1 (91)

$R^{1}=(E)$-cinnamoyl, $R^{2}=H$

nigroside 2 (92)

$R^{1}=H_{1} R^{2}=(E)$-cinnamoyl

\section{References}

' Weinges, K., von der Eltz, H., Hartz, G. (1982) Liebigs Ann. Chem. 872 .

2 Weinges, K., Braun, G., Oster, B. (1983) Liebigs Ann. Chem. 2197.

3 Strickler, H., Ohloff, G., Kovats, E. (1967) Helv. Chim. Acta 50, 759.

4 Hegnauer, R. (1966) Pharm. Acta Helv. 41, 577.

${ }^{5}$ Bobbitt, J. M., Segebarth, K. P. (1969) in: Cyclopentanoid Terpene Derivatives, (Taylor, W. I., Battersby, A. R., eds.), Marcel Dekker Inc., New York, Chapter 1.

${ }^{6}$ Sticher, O., Junod-Busch, U. (1975) Pharm. Acta Helv. 50, 127.

7 Jensen, S. R., Nielsen, B. J., Dahlgren, R. (1975) Bot. Not. 128, 148.

8 Rimpler, H. (1978) Planta Med. 33, 313.

9 El-Naggar, L. J., Beal, J. L. (1980) J. Nat. Prod. 43, 649.

10 Kaplan, M. A. C., Gottlieb, O. R. (1982) Biochem. Syst. Ecol. 10, 329.

11 Hegnauer, R. (1986) Chemotaxonomie der Pflanzen, Vol. VII, Birkhäuser Verlag, Basel, p. 325.

12 Inouye, H., Uesato, S. (1986) Prog. Chem. Org. Nat. Prod. 50, 169.

${ }^{13}$ Kapil, R. S., Brown, R. T. (1979) The Alkaloids, 17, 546.

14 Imakura, Y., Kobayashi, S., Yamahara, Y., Kihara, M., Tagawa, M., Murai, F. (1985) Chem. Pharm. Bull. 33, 2220.

15 Mc Coy, J. W., Stermitz, F. R. (1983) J. Nat. Prod. 46, 902.

16 Roby, M. R., Stermitz, F. R. (1984) J. Nat. Prod. 47, 846.

17 Stermitz, F. R., Harris, G. H., Jing, W. (1986) Biochem. Syst. Ecol. $14,499$.

18 Roby, M. R., Stermitz, F. R. (1984) J. Nat. Prod, 47, 854.

19 Endo, T., Taguchi, H. (1973) Yakugaku Zasshi 93, 30.

20 Jensen, S. R., Lyse-Petersen, S. E., Nielsen, B. J. (1979) Phytochemistry 18, 273.

21 Houghton, P. J., Lian, L. M. (1986) Phytochemistry 25, 1907.

22 Calis, I., Sticher, O. (1985) J. Nat. Prod. 48, 108.

${ }^{23}$ Murai, F., Tagawa, M., Matsuda, S., Kikuchi, T., Uesato, S., Inouye, H. (1985) Phytochemistry 24, 2329.

24 Battersby, A. R., Burnett, A. R., Knowles, G. D., Parsons, P. G. (1968) J. Chem. Soc., Chem. Commun. 1277.

${ }^{25}$ Loew, P., v. Szczepanski, Ch., Coscia, C. J., Arigoni, D. (1968) J. Chem. Soc., Chem. Commun. 1276.

${ }^{26}$ Escher, S., Loew, P., Arigoni, D. (1970) J. Chem. Soc., Chem. Commun. 823.

${ }^{27}$ Meier, B., Sticher, O. (1977) J. Chromatogr. 138, 453.

28 Miyagoshi, M., Amagaya, S., Ogihara, Y. (1986) J. Chromatogr. 357. 293.

29 Demizu, S., Ohshima, Y., Hiraga, Y., Takahashi, K. (1986) J. Chromatogr. 360, 307.

30 Sakamoto, I., Morimoto, K., Tanaka, O., Inouye, H. (1983) Chem. Pharm. Bull. 31, 25.

31 Schaufelberger, D., Hostettmann, K. (1987) J. Chromatogr. 389, 450.

32 Craig, L. C., Craig, D. (1956) in: Technique of Organic Chemistry, Vol. 3, (Weissberger, A., ed.), Interscience, New York.

33 Synder, J. K., Nakanishi, K., Hostettmann, K., Hostettmann, M., (1984) J. Liq. Chrom. 7, 243.

34 Hostettmann, K. (1980) Planta Med. 39, 1.

${ }^{35}$ Chaudhuri, R. K., Salama, O., Sticher, O. (1980) Planta Med. 40. 164.

36 Hostettmann, K., Hostettmann-Kaldas, M., Sticher, O. (1979) Helv. Chim. Acta 62, 2079.

37 Hostettmann, K., Hostettmann-Kaldas, M., Sticher, O. (1979) J. Chromatogr. 186, 529.

38 Gross, G.-A. (1985) Thesis, ETH No. 7800, Zürich.

${ }^{39}$ Schaufelberger, D., Hostettmann, K. (1985) J. Chromatogr. 346, 396.

40 Kaizuka, H., Takahashi, K. (1983) J. Chromatogr. 258, 135.

41 Dallenbach-Toelke, K., Niyredy, Sz., Sticher, O. (1987) J. Chromatogr. 404, 365.

42 Niyredy, Sz., Erdelmeier, C. A. J., Dallenbach-Toelke, K., NiyredyMikita, K., Sticher, O. (1986) J. Nat. Prod. 49, 885.

${ }^{43}$ Niyredy, Sz., Erdelmeier, C. A. J., Meier, B., Sticher, O. (1985) Planta Med. 241.

44 Erdelmeier, C. A. J., Kinghorn, A. D., Farnsworth, N. R. (1987) J. Chromatogr. 389, 345 .

45 Schilling, G., Henkels, W.-D., Künstler, K., Weinges, K., Kloss, P., Jaggy, H. (1975) Liebigs Ann. Chem. 230.

46 Bailleul, F., Delaveau, P., Rabaron, ., Platt, M., Koch, M. (1977) Phytochemistry 16, 723.

47 Bock, K., Jensen, S. R., Nielsen, B. J., Norn, V. (1978) Phytochemistry 17,753 . 
48 Chaudhuri, R. K., Afifi-Yazar, F. Ü., Sticher, O. (1979) Helv. Chim. Acta 62, 1603.

49 Tietze, L.-F., Niemeyer, U., Marx, P., Glüsenkamp, K.-H. (1980) Tetrahedron $36,1231$.

50 Chaudhuri, R. K., Afifi-Yazar, F. Ü., Sticher, O. (1980) Tetrahedron $36,2317$.

51 Damtoft, S., Jensen, S. R., Nielsen, B. J. (1981) Phytochemistry 20, 2717.

52 Bianco, A., Caciola, P., Guiso, M., Iavarone, C., Trogolo, C. (1981) Gazz. Chim. Ital. 111, 201.

53 Damtoft, S., Jensen, S. R., Nielsen, B. J. (1982) Tetrahedron Lett. 23, 1215.

54 Bianco, A., Passacantilli, P., Polidori, G. (1983) Org. Magn. Res. 21, 460 .

55 Bianco, A., Passacantilli, P., Polidori, G. (1983) Gazz. Chim. Ital $113,829$.

56 Christl, M., Reich, H. J., Roberts, J. D. (1971) J. Am. Chem. Soc. 93 3463.

57 Bianco, A., Guiso, M., Iavarone, C., Massa, M., Trogolo, C., Oguakwa, J. U., Francesconi, A. (1982) Gazz. Chim. Ital. 112, 199.

58 Jensen, S. R., Nielsen, B. J. (1982) Phytochemistry 21, 1623.

${ }^{59}$ Bock, K., Pedersen, C. (1974) J. Chem. Soc., Perkin Trans. 2, 293.

60 Thies, P. W., Finner, E., David, S. (1981) Planta Med. 41, 15.

61 Junior, P. (1983) Habilitationsschrift, Marburg.

${ }^{62}$ Gering, B. (1987) Thesis, Marburg.

${ }^{63}$ Le Cocq, C., Lallemand, J.-Y. (1981) J. Chem. Soc., Chem. Commun. 150.

${ }^{64}$ Brown, D. W., Nakashima, T. T., Rabenstein, D. L. (1981) J. Magn. Res. 45, 302.

65 Benn, R., Günther, H. (1983) Angew. Chem. 95, 381.

${ }^{66}$ Shoolery, J. N. (1984) J. Nat. Prod. 47, 226.

67 Ernst, R. R. (1987) Chimia 41, 323.

${ }^{68}$ Bax, A. R., Griffey, H., Hawkins, B. C. (1983) J. Magn. Res. 55, 301.

${ }^{69}$ Berger, S., Diehl, B. W. K. (1988) GIT Fachz. Lab. 32, 305.

70 Junior, P. (1989) Planta Med 55, 83.

71 Sati, O. P., Chaukiyal, D. C., Nishi, M., Miyahara, K., Kawasaki, T. (1986) Phytochemistry 25, 2658.

72 Gross, G. -A., Sticher, O., Anklin, C. (1986) Helv. Chim. Acta 69, 156.

${ }^{73}$ Gross, G.-A., Sticher, O., Anklin, C. (1987) Helv. Chim. Acta 70, 91.

${ }^{74}$ Richarz, R., Wüthrich, K. (1978) J. Magn. Res. 30, 147.

75 Macura, S., Wüthrich, K., Ernst, R. R. (1982) J. Magn. Res. 46, 269.

76 Bigler, P., Kamber, M. (1985) Angew. Chem. 97, 701.

77 Milz, S., Rimpler, H. (1979) Z. Naturforsch. 34c, 319

78 Junior, P. (1981) Planta Med. 42, 104.

79 Jensen, S. R. (1983) Phytochemistry 22, 1761.

80 Imakura, Y., Kobayashi, S., Kida, K., Kido, M. (1984) Phytochemistry 23,2263 .

81 Franke, A., Rimpler, H. (1986) Planta Med. 89.

${ }^{82}$ Stenzel, E., Rimpler, H., Hunkler, D. (1986) Phytochemistry 25, 2557.

${ }^{83}$ Mikhova, B. P., Handjieva, N. V., Popov, S. S., Spassov, S. L. (1987) J. Nat. Prod. 50, 1141.

${ }^{84}$ Handjieva, N. V., Mollova, N. N., Popov, S. S. (1986) Biomed. Mass Spectr. 13, 159.

${ }^{85}$ Popov, S. S., Handjieva, N. V. (1983) Mass Spectrom. Rev. 2, 481.

${ }^{86}$ Schaufelberger, D., Domon, B., Hostettmann, K. (1984) Planta Med. $50,398$.

${ }^{87}$ Fenselau, C. (1984) J. Nat. Prod. 47, 215.

${ }^{88}$ Garcia, J., Chulia, A. J. (1986) Planta Med. 327.

${ }^{89}$ Gering, B., Junior, P., Wichtl, M. (1987) Phytochemistry 26, 3011

${ }^{90}$ Gering, B., Junior, P., Wichtl, M. (1987) Phytochemistry 26, 753.

91 Takeda, Y., Tsuchida, S., Fujita, T. (1987) Phytochemistry 26, 2303.

92 Schaufelberger, D., Gupta, M. P., Hostettmann, K. (1987) Phytochemistry $26,2377$.

93 Garcia, J., Chulia, A. J. (1987) Planta Med. 53, 101.

94 Seifert, K., Schmidt, J., Lien, N. T., Johne, S. (1985) Planta Med, 409.

95 Cornelis, A., Chapelle, J. P. (1976) Pharm. Acta Helv. 51, 177.

96 Bock, K., Jensen, S. R., Nielsen, B. J. (1976) Acta Chem. Scand. B 30 , 743.

97 Uesato, S., Hashimoto, T., Takeda, Y., Uobe, K., Inouye, H. (1981) Chem. Pharm. Bull. 29, 3421.

${ }^{98}$ Kobayashi, H., Karasawa, H., Miyase, T., Fukushima, S. (1984) Chem. Pharm. Bull. 32, 1729.

99 Yoshikawa, M., Fukuda, Y., Taniyama, T., Kitagawa, I. (1986) Chem. Pharm. Bull. 34, 1403.
100 Dutta, P. K., Chowdhury, U. S., Chakravarty, A. K., Achari, B., Pakrashi, S. C. (1983) Tetrahedron 39, 3067.

101 Bianco, A., Bonini, C. S., Iavarone, C., Trogolo, C. (1982) Phytochemistry 21,201

102 Bernini, R., lavarone, C., Trogolo, C.(1984) Phytochemistry 23, 1431.

103 Murai, F., Tagawa, M. (1979) Planta Med. 37, 234.

104 Murai, F., Tagawa, M., Inouye, H., Ishida, T., Inoue, M. (1987) Chem. Pharm. Bull. 35, 2533.

105 Ohashi, H., Tsurushima, T., Ueno, T., Fukami, H. (1986) Agric. Biol. Chem. 50, 2655.

106 Sakai, T., Nakajima, K., Sakan, T. (1980) Bull. Chem. Soc. Jpn. 53, 3683.

107 Uesato, S., Xie, S., Inouye, H., Shingu, T., Inoue, M., Doi, M. (1987) Phytochemistry 26, 561 .

108 Xie, S., Uesato, S., Inouye, H., Fujita, T., Murai, F., Tagawa, M., Shingu, T. (1988) Phytochemistry 27, 469.

109 Xu Chengjun, Zeng Xianyi, Yu Dequan (1985) Yaoxue Xuebao 20, 652 , C. A. $107,93475$.

110 Junior, P. (1989) Planta Med. 55, 81.

111 Jensen, S. R., Kirk, O., Nielsen, B. J., Norrestam, R. (1987) Phytochemistry 26, 1725

112 Franke, A., Rimpler, H, (1987) Phytochemistry 26, 3015.

113 Liang Wenzao, Ling Dakui, Tian Songjiu, Tu Guoshi (1986) Yaoxue Xuebao 21, 906.

114 Gross, G.-A., Sticher, O. (1986) Helv. Chim. Acta 69, 1113.

115 Hase, T., Takao, H., Iwagawa, T. (1983) Phytochemistry 22, 1977.

116 Bianco, A., Passacantilli, P., Righi, G., Nicoletti, M., Serafini, M. Garbarino, J. A., Gambaro, V. (1986) Phytochemistry 25, 946.

117 Bianco, A., Passacantilli, P., Rispoli, C. (1986) J. Nat. Prod. 49, 519.

118 Bianco, A., Passacantilli, P., Righi, G., Nicoletti, M., Serafini, M., Garbarino, J. A., Gambaro, V., Chamy, M. C. (1987) Planta Med. 53, 385.

119 Murai, F., Matsuda, S., Kikuchi, T., Uesato, S., Inouye, H. (1985) Phytochemistry 24, 2329.

120 Takagi, S., Amaki, M., Yumioka, E., Nishimura, T., Sakina, K. (1982) Yakugaki Zasshi 102, 313, C. A. 97, 52511q.

121 Bianco, A., Passacantilli, P., Nicoletti, M., Alvez de Lima, R. (1982) Planta Med. 46, 33.

122 Junior, P. (1983) Planta Med. 47, 67.

${ }^{123}$ Nicoletti, M., Serafini, M., Tomassini, L., Bianco, A., Passacantilli, P. (1987) Planta Med. 53, 295

124 Inoue, K., Tanahashi, T., Inouye, H. (1985) Phytochemistry 24, 1299.

125 Tanahashi, T., Nagakura, N., Inoue, K., Inouye, H., Shingu, T (1987) Chem. Pharm. Bull. 35, 5032.

126 Fukuyama, Y., Koshino, K., Hasegawa, T., Yamada, T., Nakagawa, K. (1987) Planta Med. 53, 427.

127 Junior, P. (1984) Planta Med. 50, 417.

128 Bianco, A., Bolli, D., Passacantilli, P. (1981) J. Nat. Prod. 44, 450

129 Bianco, A., Bolli, D., Passacantilli, P. (1981) Gazz. Chim. Ital. 111 91.

130 Oshio, H., Inouye, H. (1982) Phytochemistry 21, 133.

131 Marco, J. L. (1985) Phytochemistry 24, 1609.

132 Gardner, D. R., Narum, J., Zook, D., Stermitz, F. R. (1987) J. Nat. Prod. 50, 485.

133 Ikeshiro, Y., Tomita, Y. (1987) Planta Med. 53, 158

134 Calis, I., Lahloub, M., Sticher, O. (1984) Helv. Chim. Acta 67, 160.

135 Shen, Y. C., Chen, C. H. (1986) T'ai-wan Yao Hsueh Tsa Chih 38, 203; C. A. 107, 214791 (1987).

136 Inoue, K., Tanahashi, T, Inouye, H., Murai, F., Tagawa, M. (1982) Phytochemistry 21, 359 .

137 Bock, K., Jensen, S. R., Nielsen, B. J., Norn, V. (1978) Phytochemistry 17,753 .

138 Kitagawa, I., Hino, K., Nishimura, T., Iwata, E., Yosioka, I. (1971) Chem. Pharm. Bull. 19, 2534

139 Wagner, H., Vasirian, K. (1974) Phytochemistry 13, 615.

140 Inouye, H., Ueda, S., Nakamura, Y., Inoue, K., Hayano, T., Matsamura, H. (1974) Tetrahedron 30,571.

141 Ikeshiro, Y., Tomita, Y. (1985) Planta Med. 390

142 Seifert, K., Schöpp, E., Johne, S., Hesse, M. (1982) Helv. Chim. Acta 65,1678 .

143 Verma, K. S., Jain, A. K., Gupta, S. R. (1986) Planta Med. 359.

144 Garcia, J., Chulia, A. J. (1987) Planta Med. 53, 101

145 Van der Sluis, W. G., Labadie, R. P. (1981) Planta Med. 41, 150.

146 Chulia, A. J., Kaouadji, M. (1985) J, Nat. Prod. 48, 54. 